\title{
LETTERS
}

\section{Alopecia areata and relapsing polychondritis or mosaic autoimmunity? The first experience of co-trimoxazole treatment}

\author{
A P Rozin, D Schapira, R Bergman
}

Ann Rheum Dis 2003;62:778-780

\begin{abstract}
A 13 year old girl presented with auricular chondritis and recurrent episodes of unexplained chest pain, arthritis, bronchitis, conjunctivitis, prolonged steroid resistant alopecia areata, and a history of recurrent tonsillitis. Both the mosaic of autoimmunity and relapsing polychondritis were considered in the differential diagnosis. The patient was successfully treated with co-trimoxazole. The significance of co-trimoxazole, which is an antibiotic and an immunomodulatory drug, in the treatment of autoimmune disease is discussed.
\end{abstract}

T he term "mosaic of autoimmunity", introduced by Shoenfeld and Isenberg in 1989, implies clustering of several autoimmune diseases in a single patient. Relapsing polychondritis (RP) is a rare episodic inflammatory disease, which affects the cartilage of ears, respiratory tract, joints, and vessels and may be fatal. Drug treatment may control the disease activity in only some patients. ${ }^{1}$ Alopecia areata (AA) affects anagen hair bulbs. $\mathrm{T}$ cell mediated and antibody dependent mechanisms have been suggested. ${ }^{23}$ Glucocorticoids, anthralin, or minoxidil stimulate hair growth but do not prevent hair loss. ${ }^{2}$ AA has been described in association with other autoimmune disorders. We believe this to be the first reported case in which AA is associated with auriculum chondritis and mosaic of autoimmunity which responded to co-trimoxazole treatment.

\section{CASE REPORT}

A 13 year old girl presented with acute inflammation of the left external ear. She had acute tonsillitis two weeks before the symptoms appeared, which was treated. Five years earlier the patient had recurrent attacks of chest pain, which resolved spontaneously. Four years earlier she began to have episodes of mono-oligoarthritis which resolved after 3-4 days. She had a long term history of recurrent tonsillitis. $\beta$-Haemolytic streptococcus was only once isolated on culture. Acute tonsillitis preceded episodes of arthritis on several occasions. Several events of acute bronchitis and recurrent conjunctivitis occurred during this period. Retinal examination was unremarkable.

Twenty months before the chondritis a large patch of AA appeared. Applications with betamethasone cream and $0.1-1 \%$ short contact anthralin treatment for three months failed to induce regrowth of hair. Oral prednisolone was started at an initial dose of $40 \mathrm{mg}$ a day tapered over the next three weeks. The AA disappeared, but during the following months new adjacent patches appeared. Intermittent corticosteroid treatment with oral prednisone and intralesion scalp injections of betamethasone (Celestone) every 6-8 weeks ${ }^{2}$ and local applications of $5 \%$ minoxidil spray for one and a half years promoted hair growth, yet additional patches of AA appeared.

The acute auricular inflammation, which spared the ear lobe, was diagnosed as chondritis. Intravenous amoxycillinclavulanic acid was initiated, with no response noted after one week of treatment (fig 1A). An autoimmune aetiology of the disease was suspected. Oral prednisone $40 \mathrm{mg}$ a day was instituted for five days and co-trimoxazole $50 \mathrm{mg} / \mathrm{kg} /$ day in two
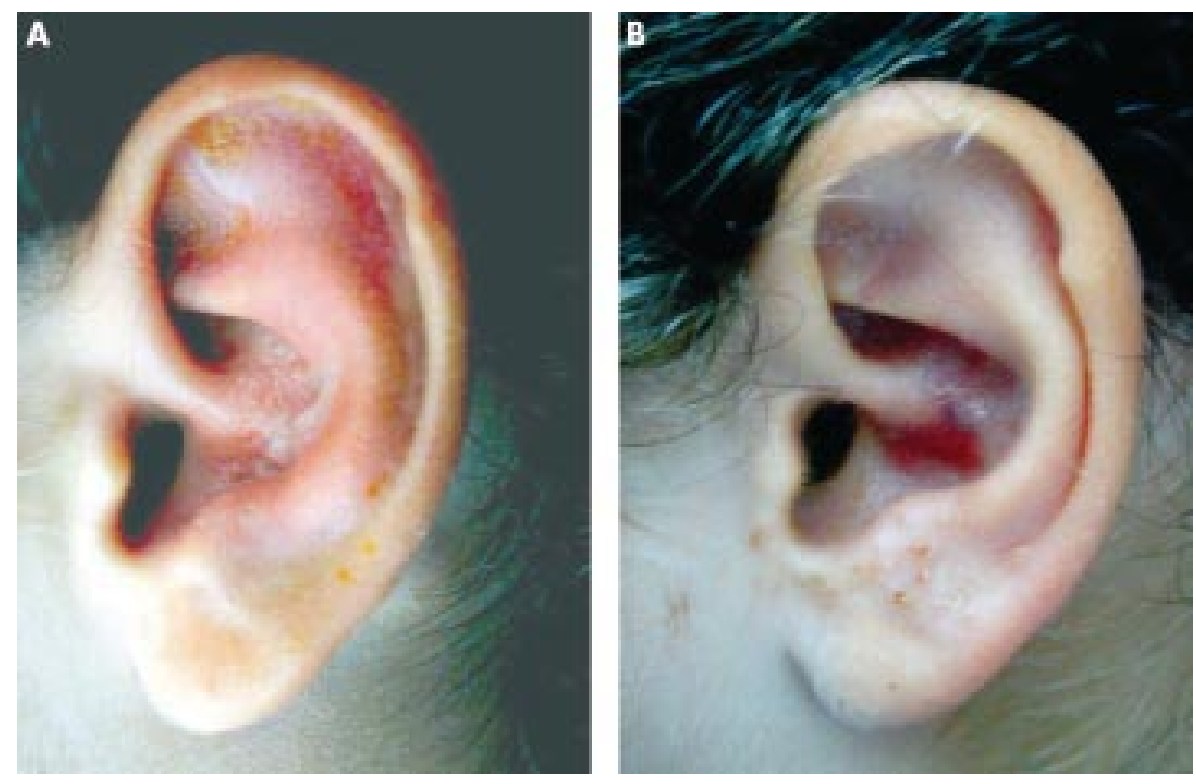

Figure 1 (A) Diffuse oedema and erythema of the auricle sparing the ear lobe are sustained after five days of intravenous augmentin (amoxycillin+clavulanic acid) treatment (1 $\mathrm{g}$ every eight hours). (B) Two days after the initiation of combined treatment with prednisone $40 \mathrm{mg} /$ day and co-trimoxazole $50 \mathrm{mg} / \mathrm{kg} /$ day, there is marked diminution of the oedema and erythema. 
divided doses was started as well. The rationale for co-trimoxazole treatment was its steroid sparing effect and antibiotic prophylaxis, which might prevent the possible adjuvant action of the pharyngeal flora on autoimmunity. ${ }^{4}$ Prompt regression of the auricular inflammation was seen two days after starting the combined treatment (fig 1B), and within a few days complete resolution of the chondritis was noted. The daily co-trimoxazole treatment was reduced to $25 \mathrm{mg} / \mathrm{kg}$ after one week, taken as single dose. Two weeks later the therapeutic policy was $25 \mathrm{mg} / \mathrm{kg}$ every other day (taken as single daily dose), and this schedule was continued for five months. Two months after the initiation of the co-trimoxazole treatment the patches of AA disappeared.

Five months after the initial episode of chondritis a routine vaccination for tetanus and poliomyelitis was performed at school. Ten days later, the signs of chondritis recurred in the same ear. The co-trimoxazole dose was increased to the initial dose $(50 \mathrm{mg} / \mathrm{kg} /$ day in two divided doses) without the addition of corticosteroids. After three days, complete recovery occurred and the alternate day dose schedule was restarted. An attempt to decrease the dose to $25 \mathrm{mg} / \mathrm{kg} /$ day twice a week for six weeks was performed but was associated with the appearance of two small foci of AA. Hair growth followed reinstitution of a daily regimen for one week followed by alternate day dose schedule (25 mg/kg/day every other day) for four weeks. During follow up, repeated tests for complete blood count, blood chemistry, antinuclear antibodies, anti-DNA, antinuclear cytoplasmic antibodies, IgG, IgA, IgM, complement, rheumatoid factor, protein electrophoresis, thyroid function were normal. Lung and heart imaging studies were unremarkable.

\section{DISCUSSION}

Mosaic of several autoimmune diseases or multiform RP should be considered when RP occurs in patients with other disease of autoimmune aetiology. No laboratory tests have been found to be diagnostic for these disorders. We propose that recurrent tonsillitis might be due to incompetent immune control of infection. IgA deficiency as a common denominator to the mosaic of autoimmunity and recurrent infections has not been detected. We treated our patient with co-trimoxazole, assuming that it might control bacterial load, on the one hand, and modulate the cellular and humoral immune response, on the other. ${ }^{4}$ This modulation may have a role in the treatment of AA, which may be transferred by T lymphocytes. ${ }^{5}$ In 1970, Ghilchik et al found that trimetoprim (component of co-trimoxazole) significantly extended the life of skin grafts transplanted from brown to white mice. ${ }^{6}$ The prolongation of the rejection time was similar to that obtained with azathioprine. Inhibition of T lymphocytes by co-trimoxazole may be responsible for both late allograft rejection and therapeutic effect in AA. Co-trimoxazole was successfully used in the treatment of other autoimmune diseases. ${ }^{4}$

Alteration of the immune process by sulfasalazine (SSZ) through inhibition of nuclear factor- $\mathrm{\kappa B}$ signalling activation, which contributes to anti-inflammatory and immunosuppressive effects, has been reported. ${ }^{7}$ In another recent study patients with severe AA received SSZ and showed 23\% of hair growth, which is cosmetically acceptable. ${ }^{8}$ Sulfonamide sulfamethoxazole may have similar properties. It is known that patients with RP have increased titres of antibodies to cartilage proteins. ${ }^{9}$ It is still unclear whether these antibodies are a result or cause of cartilage damage. These antibodies may have a role in cartilage inflammation and decrease after successful treatment. The presence of HLA-B8, DR3 has recently been found to be associated with multiple autoantibodies and autoimmunity. ${ }^{10}$ Co-trimoxazole may cause a decrease in the IgM titre during treatment. ${ }^{4}$ This may partially explain its efficacy in treating RP. After two months of co-trimoxazole treatment the steroid resistant AA was completely healed. No recurrence of tonsillitis or arthritis was noted during this
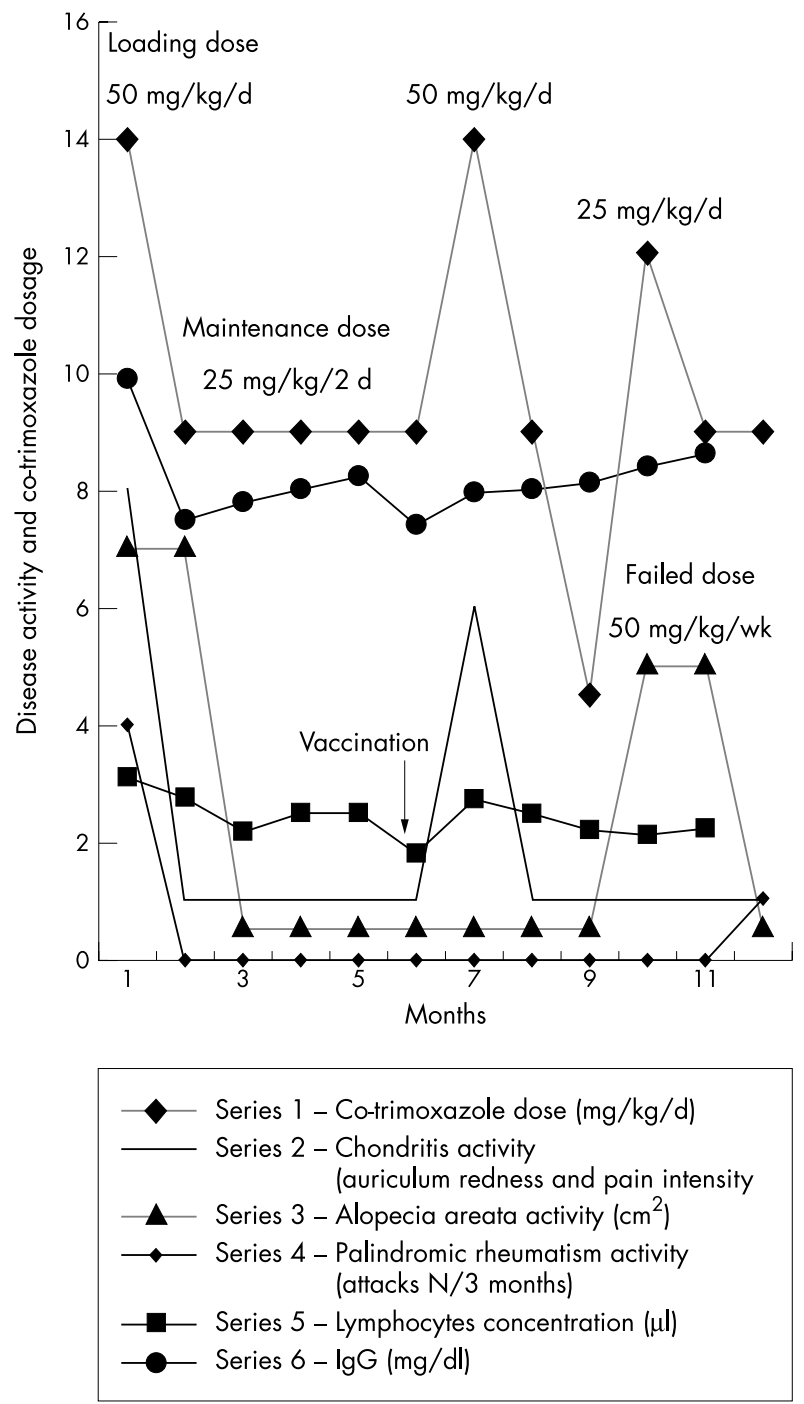

Figure 2 Monthly values of clinical features and laboratory findings.

period. Prompt resolution of relapsing chondritis and alopecia followed reinstitution of the appropriate co-trimoxazole dose. A decrease in lymphocytes blood count and serum IgG was noted during co-trimoxazole treatment (fig 2).

\section{Authors' affiliations}

A Rozin, D Schapira, The B Shine Department of Rheumatology, Rambam Medical Centre and Faculty of Medicine, Technion-Israel Institute of Technology, Haifa, Israel

R Bergman, Department of Dermatology, Rambam Medical Centre and Faculty of Medicine, Technion-Israel Institute of Technology, Haifa, Israel

Correspondence to: Dr A Rozin; nahir@rambam.health.gov.il

Accepted 21 January 2003

\section{REFERENCES}

1 Letko E, Zafirakis P, Baltatzis S, Voudouri A, Livir-Rallatos C, Foster CS Relapsing polychondritis: a clinical review. Semin Arthritis Rheum 2002;31:384-95.

2 Price VH. Treatment of hair loss. N Engl J Med 1999;341:964-73.

3 Todes-Taylor N, Turner R, Wood GS, Stratte PT, Morhenn VB. T cell subpopulation in alopecia areata. I Am Acad Dermatol

1984; 11:216-23.

4 Rozin A, Schapira D, Braun-Moscovic YA, Nahir M. Cotrimoxazole treatment for rheumatoid arthritis. Semin Arthritis Rheum 2001;31:133-41.

5 Gilhar A, Ullman Y, Berkutzki T, Assy B, Kalish RS. Autoimmune hair los (alopecia areata) transferred by $T$ lymphocytes to human scalp explants on SCID mice. J Clin Invest 1998;101:62-7. 
6 Ghilchik MW, Morris AS, Reeves DS. Immunosuppressive powers of the antibacterial agent trimetoprim. Nature 1970;227:393-4.

7 Weber CK, Liptay S, Wirth T, Adler G, Schmid RM. Suppression of NF- $\kappa B$ activity by sulfasalazine is mediated by directed inhibition of $1 \kappa B$ kinases $\alpha$ and $\beta$. Gastroenterology 2000;1 19:1209-18.

8 Ellis CN, Brown MF, Voorhees JJ. Sulfasalazine for alopecia areata. J Am Acad Dermatol 2002;46:541-4.
9 Hansson AS, Heinegard D, Piette JC, Burkhardt H, Holmdahl R. The occurrence of autoantibodies to matrilin 1 reflects a tissue-specific occurrence of autoantibodies to matrilin 1 reflects a tissue-specific
response to cartilage of the respiratory tract in patients with relapsing response to cartilage of the respiratory tract in patients
polychondritis. Arthritis Rheum 2001:44:2402-12.

10 Rahamim-Cohen D, Shoenfeld Y. The mosaic of autoimmunity a classical case of inhalation of a polyclonal activating factor in a genetically and hormonally susceptible patient leading to multiple autoimmune diseases. Isr Med Assoc J 2001:3:381-2.

\section{An unusual case of ANCA positive disease}

\section{S Delen, A Boonen, R Landewé, A A Kroon, Si van der Linden, J W Cohen Tervaert}

Ann Rheum Dis 2003;62:770-781

W report here on a patient in whom induction of myeloperoxidase-antineutrophil cytoplasmic antibodies (MPO-ANCA) occurred simultaneously with the development of pseudovasculitis due to the cholesterol emboli syndrome.

\section{CASE REPORT}

A 65 year old woman was admitted in August 2001 because of fatigue, weight loss, and oligoarthritis. She had a history of hypertension for which she was treated with captopril and hydrochlorothiazide. On examination she had acrocyanosis, livedo reticularis, a blood pressure of 220/1 10 on both arms, vascular bruits over the carotid and femoral arteries, and arthritis of the right wrist and both knees. The erythrocyte sedimentation rate (ESR) was $70 \mathrm{~mm} / \mathrm{lst} \mathrm{h}, \mathrm{C}$ reactive protein (CRP) 75 $\mathrm{mg} / \mathrm{l}$, haemoglobin $7.1 \mathrm{mmol} / \mathrm{l}$, and white blood cell count $10.8 \times 10^{9} /$. Serum creatinine was normal and there were no abnormalities on urine analysis. Rheumatoid factor, antinuclear antibodies, ANCA, cryoglobulins, and anticardiolipin antibodies tested negative. Systemic vasculitis was suspected, but a deep muscle biopsy disclosed no abnormalities. Arteriography showed generalised atherosclerosis with bilateral stenosis of the renal arteries but no (micro-) aneurysms of the visceral arteries. Captopril was replaced by nifedipine and a bilateral stenting procedure of the renal arteries was performed, which improved the blood pressure. Because of persistent undifferentiated oligoarthritis, hydroxychloroquine was started.

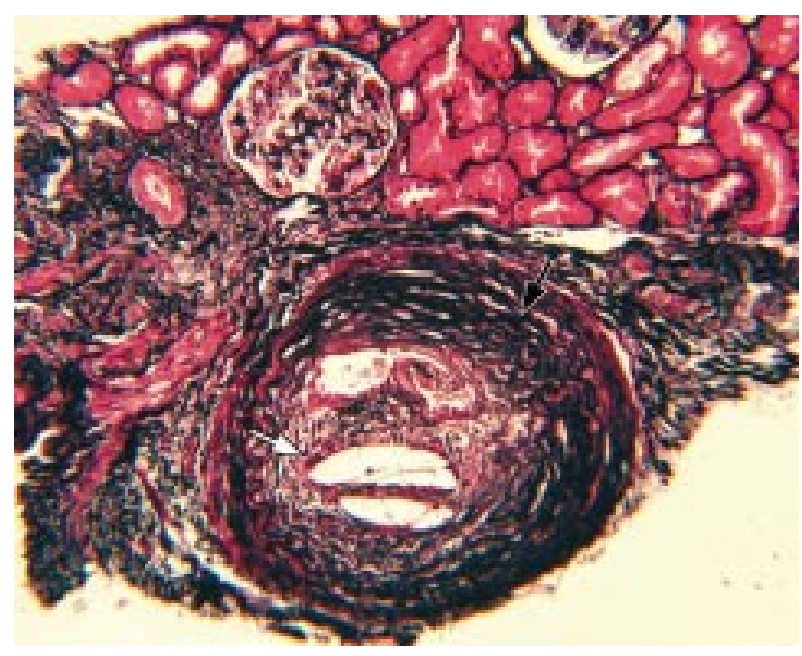

Figure 1 Kidney biopsy specimen showing cholesterol embolism (white arrow) in afferent arteriole with surrounding fibrosis (black arrow) (silvernitrate, $\times 320$ ).
Two months later, the patient was readmitted because of fever, myalgia, and progressive renal failure. Shortly after admission she developed chest pain due to pleuropericarditis. The ESR was $132 \mathrm{~mm} / \mathrm{lst}$ h, CRP $217 \mathrm{mg} / \mathrm{l}$, haemoglobin 5.7 $\mathrm{mmol} / \mathrm{l}$, white blood cell count $19 \times 10^{9} / \mathrm{l}$, and serum creatinine was $263 \mu \mathrm{mol} / \mathrm{l}$. Proteinuria was $300 \mathrm{mg} / \mathrm{l} / 24 \mathrm{~h}$ without erythrocyturia. Pleural fluid showed an exudate without malignant cells. All cultures remained sterile. On immunological testing a perinuclear ANCA was now detected and an enzyme linked immunosorbent assay (ELISA) showed that the MPOANCA was 39 arbitrary units (AU). Fundoscopy was normal and no vegetations were detected by echocardiography. Endoscopy of the nose, including biopsy samples, showed no abnormalities. A kidney biopsy showed multiple cholesterol emboli (fig 1). Because of persistent pleuritis, prednisolone $20 \mathrm{mg}$ a day was started. At that time, renal function had already ameliorated spontaneously. During follow up in an outpatient department, the clinical condition of the patient improved further. At the last visit in March 2002, prednisolone was stopped. CRP had normalised and renal function stabilised at a serum creatinine around $140 \mu \mathrm{mol} / \mathrm{l}$. The MPO-ANCA level was still positive at 22 AU in January and had become negative in March 2002.

\section{DISCUSSION}

Cholesterol emboli syndrome usually occurs in patients with severe atherosclerosis and is triggered in one third of patients by arteriography or an endovascular procedure. ${ }^{1}$ Apart from the classical features, including acrocyanosis, livedo reticularis, and progressive renal failure, it may produce a variety of symptoms mimicking vasculitis. ${ }^{2}$ Symptoms are caused by direct embolisation of the small and middle sized arteries. In addition, the presence of cholesterol emboli within the vascular lumen can trigger an inflammatory reaction.

Fever, weight loss, myalgia, leucocytosis, and raised ESR and CRP are well recognised manifestations of "pseudovasculitis" due to cholesterol emboli. Eosinophilia and hypocomplementaemia are often associated, though not in our patient. Pleuropericarditis has not yet been reported as a manifestation of pseudovasculitis due to cholesterol emboli. Isolated pleuritis was described in one case. ${ }^{3}$ ANCA positivity has been reported occasionally. ${ }^{124}$ In most of these cases ANCA was directed against MPO, as in our case. However, the induction of ANCA was not documented during the course of the cholesterol emboli syndrome in any of the patients.

Recently it has been shown that ANCA is not more prevalent in patients with atherosclerosis than in a human control group. ${ }^{5}$ In vasculitis, a pathophysiological role for MPO-ANCA has been suggested by several authors. ${ }^{67}$ It was demonstrated that the transfer of MPO to non-immunised mice results in the development of vasculitis. ${ }^{7}$ Our patient initially had a mild vasculitis-like disease, probably due to cholesterol emboli, and 
after stent placement a full blown vasculitis-like syndrome developed. We suggest that stent placement enhanced induction of MPO-ANCA during neutrophil activation because of vessel wall damage, similar to the development of MPO-ANCA in drug induced lupus. ${ }^{8}$ Finally, MPO-ANCA further triggered the full blown vasculitis syndrome.

\section{Authors' affiliations}

S Delen, A Boonen, R Landewé, Si van der Linden, Department of Internal Medicine, Division of Rheumatology, University Hospital Maastricht, The Netherlands

A A Kroon, Department of Internal Medicine, Division of Vascular Medicine, University Hospital Maastricht, The Netherlands

J W Cohen Tervaert, Department of Internal Medicine, Division of Clinical and Experimental Immunology, University Hospital Maastricht, The Netherlands

Correspondence to: Dr A Boonen, Department of Internal Medicine, Division of Rheumatology, University Hospital Maastricht, PO Box 5800 6202 AZ Maastricht, The Netherlands; aboo@sint.azm.nl

\section{REFERENCES}

1 Maeshima E, Yamada Y, Mune M, Yukawa S. A case of cholesterol embolism with ANCA treated with corticosteroid and cyclophosphamide. Ann Rheum Dis 2001:60:726.

2 Peat DS, Mathieson PW. Cholesterol emboli may mimic systemic vasculitis. BM 1996;313:546-7.

3 Sypkens Y, Westendorp R, van Kemenade F, van Duinen S, Breedveld F. Vasculitis due to cholesterol embolism. Am J Med 1997;102:302-3.

4 Kaplan-Pavlovcic S, Vizjak A, Vene N, Ferluga D. Antineutrophil cytoplasmic autoantibodies in atheroembolic disease. Nephrol Dial Transplant 1998;13:985-7.

5 Van Haelst PL, Asselbergs FW, Van Doormaal JJ, Veeger NJGM, May $J F$, Holvoet $P$, et al. Antineutrophil cytoplasmic antibodies in patients with premature atherosclerosis: prevalence and association with risk factors. J Intern Med 2002;251:29-34

6 Heeringa P, Brouwer E, Cohen Tervaert JW, Weening JJ, Kallenberg CG. Animal models of anti-neutrophil cytoplasmic antibody associated vasculitis. Kidney Int 1998;53:253-63.

7 Xiao H, Heeringa P, Hu P, Liu Z, Zhao M, Aratani Y, et al. Antineutrophilic cytoplasmic autoantibodies specific for myeloperoxidase cause glomerulonephritis and vasculitis in mice. J Clin Invest $2002 ; 110: 955-63$

8 Jiang $\mathbf{X}$, Khursigara G, Rubin R. Transformation of lupus-inducing drugs to cytotoxic products by activated neutrophils. Science 1994;266:810-3.

\section{Platelet GPIIb/IIla (P1A $\left.{ }^{1 / 2}\right)$ polymorphism in SLE: clinical and laboratory association}

\section{B Tolusso, M Fabris, E Gremese, M Mosca, P Rovere-Querini, G F Ferraccioli}

i $\mathrm{t}$ has been reported that the level of anticardiolipin antibodies (aCL) is probably genetically determined, as HLA-DR7 (or HLA-DR4) has been shown to be associated with persistently high levels of aCL. ${ }^{1}$ No reported data are available about genetic factors implicated in ischaemic or thrombotic events in patients with systemic lupus erythematosus (SLE) without antiphospholipid antibodies (aPL).

In this study we examined the frequency of the platelet GPIIb/IIIa-PlA ${ }^{2}$ polymorphism in a series of patients with SLE. We assessed the relationship between the $\mathrm{A}^{2}$ allele prevalence ${ }^{2}$ and the clinical and immunological manifestations, as possible predisposing biological factors to major ischaemic manifestations such as central nervous system (CNS) lupus or Raynaud's phenomenon as defined according to the American College of Rheumatology (ACR) Committee. ${ }^{3}$

We studied a cohort of 109 patients with SLE attending the rheumatology referral centres of the universities of Udine, Pisa, and Milan, classified according to the ACR criteria. For comparison, 161 patients with rheumatoid arthritis (systemic inflammatory disease), 54 with systemic sclerosis (chronic ischaemic-thrombotic vasculopathy), and 128 healthy blood donors (HBD) recruited from the blood transfusion service were studied. The clinical and laboratory manifestations were

Table 1 Frequency of the PIA ${ }^{2}$ allele in SLE, RA, SSc and HBD cohorts

\begin{tabular}{llllc}
\hline $\begin{array}{l}\text { P1A }^{2} \\
\text { frequency }\end{array}$ & $\begin{array}{l}\text { SLE } \\
(n=109)\end{array}$ & $\begin{array}{l}\text { RA } \\
(n=161)\end{array}$ & $\begin{array}{l}\text { SSc } \\
(n=54)\end{array}$ & $\begin{array}{l}\text { HBD } \\
(n=128)\end{array}$ \\
\hline $\mathrm{A}^{1}$ & 69.7 & 75.2 & 81.5 & 75.8 \\
$\mathrm{~A}^{1} / \mathrm{A}^{2}$ & 28.4 & 21.7 & 18.5 & 23.4 \\
$\mathrm{~A}^{2}$ & 1.8 & 3.1 & - & 0.8 \\
\hline
\end{tabular}

carefully examined to detect a possible association between genotypes and symptoms, signs, and immunological characteristics. In particular, we focused on nephritis, vasculitis, Raynaud's phenomenon, and CNS major neurological events, thought to be related to possible ischaemic-thrombotic mechanism; these were defined by the presence of one of the following: (a) acute cerebrovascular disease (stroke); $(b)$ seizures or chorea; $(c)$ lupus headache; $(d)$ organic brain syndrome. Anticardiolipin antibodies (enzyme linked immunosorbent assay (ELISA) assay: normal values <15 GPLU; $\beta_{2}$-glycoprotein I dependent) and or lupus anticoagulant (LAC) positivities were defined according to the most recent international consensus statement. ${ }^{4}$ In the study aPL were considered positive when aCL or LAC were positive on two consecutive occasions over a six week period. Antibodies to DNA were tested either on Crithidia or in an ELISA assay (normal values $<30 \mathrm{IU} / \mathrm{ml}$ ). When one or the other was positive antibodies to DNA were considered positive in this study. The analysis of the $\mathrm{PlA}^{2}$ gene polymorphism was performed after DNA extraction following the restriction fragment length polymorphism method as reported by Weiss et al. ${ }^{2}$

Statistical analysis was performed using the Prism software (Graph-Pad, San Diego, CA 92121, USA), which automatically calculated the odds ratios (OR) and confidence intervals (CI) with the statistical significance.

Patients with SLE had a mean (SD) age of 41.6 (14.6), mean (SD) disease duration 8.9 (7.0) years; $34(31 \%)$ had nephritis, 21 (19\%) major CNS events, 20 (18\%) arthritis, 41 (38\%) Raynaud's phenomenon (Ray), 105 (96\%) antinuclear antibodies, $64(59 \%)$ antibodies to dsDNA, and 56 (51\%) aPL (aCL or LAC, or both, positive). Table 1 shows that the frequency of the $\mathrm{A}^{2}$ allele tended to be slightly increased in patients with SLE compared with HBD (OR=1.30, 95\% CI 0.7 to 2.0$)$, whereas in patients with systemic sclerosis the opposite trend was seen $(\mathrm{OR}=0.7)$. The same trend was seen for the $\mathrm{A}^{2}$ homozygosity 
Table 2 Distribution of some clinical and immunological manifestations in aPL+ patients with the $\mathrm{A} 2$ allele subgroup and $\mathrm{aPL} \pm$ without the $\mathrm{A}^{2}$ allele subgroup of patients with SLE. The odd ratios (OR) are shown

\begin{tabular}{lllll}
\hline & $\begin{array}{l}\text { SLE aPL+ with A2 } \\
\text { allele }(n=20)(\%)\end{array}$ & $\begin{array}{l}\text { SLE aPL } \pm \text { without A2 } \\
\text { allele }(n=89)(\%)\end{array}$ & OR (95\% Cl) & p Value \\
\hline CNS events+ & 25.0 & 18.0 & $1.5(0.5$ to 4.7$)$ & NS \\
Ray + & 50.0 & $\mathbf{2 3 . 6}$ & $\mathbf{2 . 8}(1.0$ to 7.5$)$ & $\mathbf{0 . 0 4}$ \\
Nephritis+ & 30.0 & 31.5 & $0.9(0.3$ to 2.7$)$ & NS \\
Vasculitis+ & 20.0 & 16.7 & $1.2(0.3$ to 5.0$)$ & NS \\
\hline
\end{tabular}

in SLE ( OR=2.4, 95\% CI 0.2 to $26.6, \mathrm{p}=\mathrm{NS})$ as well as in rheumatoid arthritis (OR=4.1, 95\% CI 0.5 to $35.3, \mathrm{p}=\mathrm{NS}$ ). The $\mathrm{A}^{2}$ allele was found to be more represented in the aPL positive than in the aPL negative patients $(\mathrm{OR}=1.7,95 \% \mathrm{CI} 0.7$ to 3.9 , $\mathrm{p}=\mathrm{NS}$ ) and in Ray+ compared with Ray- patients (OR=1.7, 95\% CI 0.7 to 3.9, $\mathrm{p}=\mathrm{NS}$ ). CNS events were far more often seen in aPL positive than negative patients as expected $(\mathrm{OR}=2.9$, $95 \%$ CI 1.0 to $8.1, p=0.04$ ). In addition, subjects carrying the $\mathrm{A}^{2}$ allele in association with the aPL positivity have an increased risk of developing Raynaud's phenomenon $(\mathrm{OR}=2.8,95 \%$ CI 1.0 to $7.5, \mathrm{p}=0.04)$, whereas no association was found with CNS events, nephritis, cutaneous vasculitis (table 2). Antiphospholipid antibody positivity did not correlate with Raynaud's phenomenon.

In SLE some patients in whom CNS ischaemic events occur, have no increases of aPL, and other factors should be considered as pathogenic. To clarify this point we considered the issue of possible genetic risks and we focused on the genetic features of the $\mathrm{PlA}^{2}$ allele polymorphism, which has been suggested as a predisposing factor either for myocardial or for CNS events. ${ }^{5}$ In this study we examined the prevalence of the $\mathrm{A}^{2}$ allele and its relationship with clinical manifestations. The $\mathrm{PlA}^{2}$ genetic setting (C to T replacement at nucleotide 1565) in platelet glycoprotein (GP)IIb/IIIa (integrin $\alpha_{\text {шь }} \beta_{3}$ ) has been commonly reported as a possible risk factor for CNS and coronary ischaemic events, especially in younger patients.

We observed a trend towards an increased frequency of the $\mathrm{A}^{1} / \mathrm{A}^{2}-\mathrm{A}^{2} / \mathrm{A}^{2}$ genotypes in patients with SLE with Raynaud's phenomenon and mostly in those with aPL. Activated GPIIb/ IIIa receptor mediates platelet aggregation and stable adhesion through the interaction with von Willebrand factor and fibrinogen. When codified by the $\mathrm{PlA}^{2}$ allele, this integrin has been shown to bind more tightly to immobilised fibrinogen and to enhance platelet reactivity. ${ }^{6}$ Therefore the $\mathrm{A}^{2}$ allele might predispose to vascular damage and in association with aPL to a vasospastic phenomenon. Our data appear complementary to a previous report from the Baltimore group, ${ }^{7}$ in which the frequency of the $\mathrm{PlA}^{1}$ and $\mathrm{PlA}^{2}$ alleles was compared in aPL positive patients with and without thrombosis. In the subgroup with arterial thrombotic events 33\% were homozygous or heterozygous for the $\mathrm{PlA}^{2}$ allele, whereas only
$19 \%$ of the patients without thrombosis possessed the allele. The major conclusion was that although platelet GPIIIa polymorphism was not a major risk factor for all thrombosis in patients with aPL, a possible association with arterial thrombosis could be considered.

Further studies dealing with factors released from platelets of carriers of the $\mathrm{A}^{2}$ allele should be performed to define fully the functional role of the polymorphism in diseases like SLE. Our data suggest that the $\mathrm{PlA}^{2}$ allele defines a subset of patients with SLE with the following characteristics: higher risk of aPL positivity and presence of Raynaud's phenomenon.

\section{Authors' affiliations}

B Tolusso, M Fabris, E Gremese, G F Ferraccioli, Division of Rheumatology, DPMSC, University of Udine, Italy

M Mosca, Division of Rheumatology, University of Pisa, Italy

P Rovere-Querini, Department of Internal Medicine, Ospedale S Raffaele, University of Milan, Italy

Correspondence to: Dr G F Ferraccioli, Department of Internal Medicine, University of Udine, 33100 Udine, Italy; gf.ferraccioli@med.uniud.it

Accepted 23 December 2002

\section{REFERENCES}

1 Savi M, Ferraccioli GF, Neri TM, Zanelli P, Dall'Aglio PP, Tincani A, et al. HLA-DR antigens and anticardiolipin antibodies in northern Italian systemic lupus erythematosus patients. Arthritis Rheum 1988;31:1568-70

2 Weiss EJ, Bray PF, Tayback M. A polymorphism of a platelet glycoprotein receptor as an inherited risk factor for coronary thrombosis. N Engl J Med 1996;334:1090-4.

3 ACR, ad hoc Committee on Neuropsychiatric Lupus Nomenclature. The American College of Rheumatology Nomenclature and case definitions for neuropsychiatric lupus syndromes. Arthritis Rheum 1999:42:599608.

4 Wilson WA, Gharavi AE, Koike T, Lockshin MD, Branch DW, Piette JC, et al. International consensus statement on preliminary classification criteria for definite antiphospholipid syndrome. Arthritis Rheum 1999:42:1309-11.

5 Bray PF. Platelet glycoprotein polymorphisms as risk factors for thombosis. Curr Opin Hematol 2000;7:284-9.

6 Byzova TV, Plow EF. The P1A2 allele and cardiovascular disease: the pros and cons. J Clin Invest 2000;105:697-8.

7 Sobel RE, Bray PF, Richardson C, Petri M, Salmon JE. The platelet glycoprotein Illa polymorphism P1A2 and risk of thrombotic events in patients with antiphospolipid antibodies [abstract]. Arthritis Rheum 1998;41 (suppl 9):S172. 


\section{Local infusion of infliximab for the treatment of acute joint inflammation}

\section{Bokarewa, A Tarkowski}

Ann Rheum Dis 2003;62:783-784

$\mathrm{T}$ umour necrosis factor $\alpha(\mathrm{TNF} \alpha)$ has emerged as a potent proinflammatory mediator in the inflammatory arthritides. Studies on synovial tissue from patients with rheumatoid arthritis have shown not only the presence of large amounts of TNF $\alpha$ but also demonstrated its regulatory effect on the whole network of proinflammatory cytokines present in inflamed joints. ${ }^{12}$ Consequently, TNF $\alpha$ antagonists given systemically have proved to be efficient in the treatment of chronic arthritides. ${ }^{34}$

Here we report our experience of an attempt to ameliorate arthritis locally by intra-articular administration of TNF $\alpha$ antagonists. Six patients attending the department of rheumatology at Sahlgrenska University Hospital in Göteborg, who had persistent effusions in the knee joints which were non-responsive to intra-articular steroids, received a local injection of infliximab.

\section{METHODS AND RESULTS}

Table 1 presents the diagnosis and clinical characteristics of the patients. Both the diagnosis and duration of the inflammatory joint disease were variable. All these patients had a low general activity of joint disease as assessed by the arthritis index, Health Assessment Questionnaire, low levels of acute phase reactants (erythrocyte sedimentation rate (ESR), C reactive protein), and the small numbers of white blood cells in the blood and synovial fluid. Persistent synovitis of a knee joint was the main clinical feature of their disease. A decision to inject TNF $\alpha$ antagonists locally was made after the persistent inflammation in the knee joint did not respond to two or more arthrocenteses with concomitant corticosteroid infusions during a period of six months. Patients gave their informed consent to intra-articular injection of the TNF $\alpha$ antagonists.

Infliximab (Remicade, $100 \mathrm{mg}$ ) was mixed with $10 \mathrm{ml}$ sterile water according to the instructions for intravenous infusion, and the prepared solution was injected into the knee joint as a single dose. Synovial fluid $(25-85 \mathrm{ml})$ was removed before the infliximab injection. The treatment was tolerated well by all the patients and no adverse reactions occurred locally in the injected knee or systemically during the follow up.
The effect of the infliximab injection was determined by clinical examination and by telephoning the patients. Five patients had a relapse of the synovitis in the injected knee within two weeks and the sixth patient within 6-7 weeks after the infliximab injection.

\section{DISCUSSION}

These results indicate that the effect of intra-articular treatment with TNF $\alpha$ antagonists was no better than the local injection of corticosteroids. Several reasons for this are possible:

- The degree of infusion of the antibodies is insufficient to bind the large amount of TNF $\alpha$ present in the synovial cavity. Continuous local production and release of TNF $\alpha$ overcomes the neutralising capacity of the antibodies introduced.

- Antibodies injected into the joint neutralise only TNF $\alpha$ released into the synovial fluid, but do not penetrate into the synovial tissue or act on intracellular pools of TNF $\alpha$.

- Complexes of anti-TNF $\alpha$ antibodies with TNF $\alpha$ can still reach receptors on the surface of target cells. A high local concentration of the immune complexes (anti-TNF $\alpha$ antibodies/TNF $\alpha$ ) within the joint itself induces inflammation. ${ }^{5}$

- Local processes supporting inflammation within the joints are obviously not restricted to TNF $\alpha$. The contribution of $\mathrm{TNF} \alpha$ in local inflammation is less than its systemic effect. Anti-TNF $\alpha$ antibodies do not interrupt other mechanisms supporting inflammation within the joints.

The results of our uncontrolled study do not support the use of intra-articular TNF $\alpha$ inhibitors for the treatment of acute joint inflammation.

\section{Authors' affiliations}

M Bokarewa, A Tarkowski, Department of Rheumatology, Sahlgrenska University Hospital, Göteborg, Sweden

Correspondence to: Dr M Bokarewa, Department of Rheumatology, Gulhedsgatan 10, S-413 46 Göteborg, Sweden;

maria.bokarewa@rheuma.gu.se

Accepted 6 January 2003

Table 1 Clinical and serological characteristics of the patients included in the study

\begin{tabular}{|c|c|c|c|c|c|c|c|c|c|c|}
\hline Diagnosis & Age (y) & $\mathrm{DD}(\mathrm{y})$ & DMARDs & RF & $x$ Rays & $\begin{array}{l}\text { CRP } \\
(\mathrm{mg} / \mathrm{l})\end{array}$ & $\begin{array}{l}\text { ESR mm/ } \\
1 \mathrm{st} \mathrm{h}\end{array}$ & $\mathrm{Hb}(\mathrm{g} / \mathrm{l})$ & $\begin{array}{l}\text { WBC, bl } \\
\left(\times 10^{9} / \mathrm{ml}\right)\end{array}$ & $\begin{array}{l}\text { WBC, syn } \\
\left(\times 10^{9} / \mathrm{ml}\right)\end{array}$ \\
\hline AS & 27 & 3 & Sal & Pos & NE & 5 & 2 & 154 & 5.5 & 3.3 \\
\hline $\mathrm{JCA}$ & 20 & 18 & - & $\mathrm{Neg}$ & NE & 29 & 9 & 120 & 9.1 & 4.9 \\
\hline AS & 42 & & - & $\mathrm{Neg}$ & NE & 28 & 30 & 124 & 2.2 & 2.9 \\
\hline PsA & 44 & 10 & Sal & Neg & ER & 89 & 37 & 133 & 5.7 & 16.7 \\
\hline RA & 55 & 21 & MTX & $\mathrm{Neg}$ & ER & 5 & 13 & 136 & 6.3 & 0.8 \\
\hline $\operatorname{Re} A$ & 40 & 2 & - & $\mathrm{Neg}$ & NE & 5 & 3 & 151 & 7.4 & 7.1 \\
\hline
\end{tabular}

AS, ankylosing spondylitis; JCA, juvenile chronic arthritis; PsA, psoriatic arthropathy; RA, rheumatoid arthritis; ReA, reactive arthritis; DD, disease duration; DMARDs, disease modifying antirheumatic drugs; Sal, salazopyrin; MTX, methotrexate; RF, rheumatoid factor; NE, non-erosive; ER, erosive; bl, blood; syn, synovial fluid. 


\section{REFERENCES}

1 Chu CQ, Field M, Feldmann M, Maini RN. Localization of tumor necrosis factor alpha in synovial tissues and at the cartilage-pannus junction in patients with rheumatoid arthritis. Arthritis Rheum 1991;34:1125-32

2 Taylor PC, Peters AM, Paleolog E, Chapman PT, Elliott M, McCloskey R, et al. Reduction of chemokine levels and leukocyte traffic to joints by tumor necrosis factor alpha blockade in patients with rheumatoid arthritis. Arthritis Rheum 2000:43:38-47.

3 Maini R, St Clair EW, Breedveld F, Furst D, Kalden J, Weisman M, et al. Infliximab (chimeric anti-tumour necrosis factor alpha monoclonal antibody) versus placebo in rheumatoid arthritis patients receiving concomitant methotrexate: a randomised phase III trial. ATTRACT Study Group. Lancet 1999;354:1932-9.

4 Gorman JD, Sack KE, Davis JC Jr. Treatment of ankylosing spondylitis by inhibition of tumor necrosis factor alpha. $N$ Engl J Med 2002;346: 1349-56.

5 van Lent PL, van den Bersselaar $L A$, van den Hoek $A E$, van de Loo $A A$, van den Berg WB. Cationic immune complex arthritis in mice-a new model. Synergistic effect of complement and interleukin-1. Am J Pathol 1992;140:1451-61.

\title{
Isotope bone scans: an assessment of their diagnostic use in polyarticular pain of uncertain origin
}

\author{
A Whallett, N Evans, S Bradley, P Jobanputra
}

W e set out to learn whether a technetium-99m methylene diphosphonate ( ${ }^{99 m}$ Tc MDP) bone scan, carried out in secondary care, provided diagnostic information in patients with diffuse musculoskeletal pain of obscure origin, and whether scan findings correlated with clinical diagnosis. Clinical diagnosis, based on a minimum clinical follow up of two years or at least one year after the scan, was used as a reference or "gold standard".

\section{METHODS AND RESULTS}

Criteria for inclusion were the presence of diffuse musculoskeletal pain; a scan for diagnostic uncertainty; and availability of whole body scans, including a close-up scan of the peripheral joints. Three hour images were studied. Earlier "blood pool" images were not available. Patients were excluded if scans had been carried out for a regional disorder, isolated spinal disease, Paget's disease, suspected malignancy, known arthritis or connective tissue disease, and previous disease modifying antirheumatic drug use. One researcher examined the medical records and applied the inclusion and exclusion criteria. Ethics committee approval was granted.

Two consultant radiologists read all the scans independently without reference to clinical data or the original scan report, to ensure consistency. Scans were classified according to the scheme shown in table 1 . Radiologists then met to agree a final classification, which was used against our reference standard. General practitioner records were reviewed if follow up data were inadequate in the hospital records (10 cases). Two researchers agreed the final clinical diagnosis by discussion and after independent review of the records.

Three hundred and ten ${ }^{99 \mathrm{~m}} \mathrm{Tc}$ MDP bone scans were ordered between May 1995 and August 1996, but only 135 films were available. One hundred and twenty isotope scans were found, 54 patients met inclusion criteria, but four were excluded because of incomplete records (table 1). Radiologists agreed on scan classification in $20 / 50(40 \%)$ cases ( $\kappa$ for inflammatory arthritis versus other categories 0.31). However, after conferring, the radiologists readily agreed and discrepancies arose because of difficulties in classifying osteoarthritis versus non-specific isotope uptake.

The sensitivity of an isotope bone scan for a clinical diagnosis of " inflammatory arthritis" was 13\% (agreement in 2/15; $95 \%$ confidence interval (CI) $4 \%$ to $23 \% ; \chi^{2}=0.57 ; p>0.1$ ) and the specificity $80 \%$ (agreement in $28 / 35$; $95 \%$ CI $69 \%$ to $91 \%$ ).
Table 1 Demographic, clinical, and diagnostic data Results are shown as No (\%)

\begin{tabular}{ll}
\hline Demographic and clinical & \\
Age (mean), years & 45 (range 16-67) \\
Sex (female:male) & $32: 18$ \\
Symptom duration >12 months & $41 / 50(82)$ \\
Small joint pain (including wrist) & $50 / 50(100)$ \\
Large joint pain & $47 / 50(94)$ \\
Spinal pain & $24 / 50(48)$ \\
Morning stiffness $\geqslant 30$ minutes & $17 / 27(63)$ \\
Recorded synovitis & $16 / 47(34)$ \\
Raised ESR (>25 mm/1 st h) or CRP (>10 IU/I) & $10 / 50(20)$ \\
Positive RF (Rose-Waaler or latex >1/40) & $7 / 49(14)$ \\
Positive ANA (titre >1/100) & $3 / 44(7)$ \\
Bone scan classification (agreed by two radiologists) \\
1. Normal scan & $4 / 50(8)$ \\
2. Pattern and uptake consistent with & $9 / 50(18)$ \\
inflammatory arthritis & \\
3. Pattern and uptake consistent with & $30 / 50(60)$ \\
osteoarthritis & \\
4. Other pattern of uptake or unclassified scan & $7 / 50(14)$ \\
Final clinical diagnosis & \\
Inflammatory arthritis & $15 / 50(30)$ \\
Osteoarthritis & $20 / 50(40)$ \\
No definite diagnosis or labelled "polyarthralgia'" & $11 / 50(22)$ \\
Fibromyalgia & $2 / 50(4)$ \\
Tenosynovitis & $2 / 50(4)$ \\
\hline
\end{tabular}

ESR, erythrocyte sedimentation rate; CRP, C reactive protein; $R F$, rheumatoid factor; ANA, antinuclear antibodies.

The likelihood ratio of a positive scan was 0.65 and 1.09 for a negative scan. The positive predictive value of a bone scan was $22 \%$ and the negative predictive value $68 \%$. The latter suggests that scans may be useful in excluding inflammatory arthritis, a finding consistent with an earlier report. ${ }^{1}$

\section{DISCUSSION}

Our study fell short of the ideal design for assessing the accuracy of a diagnostic test in that it was not a prospective blind comparison of a test and a reference standard in consecutive patients. ${ }^{2}$ A practical difficulty in meeting this requirement was that clinical follow up could not be applied in parallel with the test. Also, we studied relatively few patients and many films were not found. Possibly, the final clinical diagnosis was influenced by the bone scan report. Such "test review bias" is difficult to remove in evaluations of routine diagnostic tests 
and efforts to do so may ignore clinical realities. ${ }^{3}$ We hoped that bias was minimised by relying on prolonged follow up and using two assessors.

Isotope bone scans seem to have limited value in confirming or refuting a clinical diagnosis of inflammatory arthritis and, in common with other radiological examinations, are prone to substantial interobserver variation. ${ }^{5}$ Many studies of bone scans, and of other diagnostic tests, compare patients known to have disease with those free of disease, or with another disease. ${ }^{16}$ Such studies are known to overestimate test diagnostic accuracy. ${ }^{3}$ Watchful waiting may be a more appropriate clinical strategy than relying on bone scans, with appropriate intervention when diagnostic confidence increases. However, we recognise that clinicians use diagnostic tests in sequence and that test results frequently have an incremental impact on diagnostic confidence.

\section{ACKNOWLEDGEMENTS}

We are grateful to records staff in the Department of Radiology and Medical Records, Selly Oak Hospital for help with retrieval of records and radiographs. We are also grateful to the general practitioners who provided additional data.

\section{Authors' affiliations}

A Whallett, P Jobanputra, Department of Rheumatology, Selly Oak Hospital, University Hospital Birmingham NHS Trust, Raddlebarn Road, Birmingham B29 6JD, UK

N Evans, S Bradley, Department of Radiology, Selly Oak Hospital, University Hospital Birmingham NHS Trust, Raddlebarn Road,

Birmingham B29 6JD, UK

Correspondence to: Dr P Jobanputra; P.Jobanputra@bham.ac.uk

Accepted 28 April 2003

\section{REFERENCES}

1 Shearman J, Esdaile J, Hawkins D, Rosenthall L. Predictive value of radionuclide joint scintigrams. Arthritis Rheum 1982;25:83-6.

2 Jaeschke R, Guyatt G, Sackett DL. Users' guides to the medical literature. III: How to use an article about a diagnostic test. A. Are the results of the study valid? JAMA 1994;271:389-91.

3 Lijmer JG, Mol BM, Heisterkamp S, Bonsel GJ, Prins MH, van der Meulen JHP, et al. Empirical evidence of design-related bias in studies of diagnostic tests. JAMA 1999;282:1061-6.

4 Begg C. Biases in the assessment of diagnostic tests. Stat Med 1987:6:411-23.

5 Egglin TKP, Feinstein AR. Context bias. A problem in diagnostic radiology. JAMA 1996;276:1752-5.

6 van de Wiele C, van den Bosch F, Mielants $H$, Simons M, Veys EM, Dierckx RA. Bone scintigraphy of the hands in early stage lupus erythematosus and rheumatoid arthritis. J Rheumatol 1997;24:1916-21.

\title{
Leucocytoclastic vasculitis as onset symptom of ulcerative colitis
}

\author{
F Iannone, C Scioscia, A Musio, D Piscitelli, G Lapadula
}

Ann Rheum Dis 2003;62:785-786

eucocytoclastic vasculitis is a disease whose histopathological features are inflammation of postcapillary venules -with neutrophilic infiltration and nuclear debris. ${ }^{1}$ It is believed to be an immune complex disease triggered by a large array of drugs, chemicals, infections, malignancies, and systemic and autoimmune diseases. ${ }^{2}$ Various skin manifestations can be associated with inflammatory bowel disease (IBD), ${ }^{3}$ and IBD can become a diagnostic challenge when cutaneous vasculitis precedes the intestinal disease. Here, we report a case of ulcerative colitis in which the onset symptom was skin leucocytoclastic vasculitis while intestinal illness became overt two years later.

\section{CASE REPORT}

A 22 year old male patient was referred to our rheumatology unit because of a two year history of skin lesions on his legs. His family history was negative for rheumatic, skin, and bowel diseases. On admission to the hospital, a macular dark red eruption on the skin of both legs was present. These lesions, with a diameter of $1-2 \mathrm{~cm}$, were non-blanching, slightly itching, with a scabby evolution, and healed with scar formation and skin hyperpigmentation. Skin outbreak had a recurrent course. Livedo reticularis was also present. The remaining physical examination was unremarkable.

Laboratory investigations did not show any significant abnormality. Full blood count, liver and renal functions, and urine analysis were normal. The erythrocyte sedimentation rate was $2 \mathrm{~mm} / \mathrm{lst} \mathrm{h}$, C reactive protein $3 \mathrm{mg} / \mathrm{l}$, complement components C3 and C4 were normal; rheumatoid factor, cryoglobulins, antinuclear antibodies, antineutrophil cytoplasmic antibodies were negative; hepatitis $\mathrm{B}$ and $\mathrm{C}$ virus markers were absent. Skin biopsy showed vasculitis of small dermal vessels characterised by leucocytes infiltrating the vascular wall with necrotic debris (fig 1).

A diagnosis of leucocytoclastic vasculitis was made and treatment with hydroxychloroquine $(400 \mathrm{mg} / \mathrm{day})$ and oral prednisone ( $25 \mathrm{mg} /$ day, tapered over a period of two months) was given. The patient did not benefit from this treatment. Tenosynovitis of the peroneal tendons and left ankle arthritis appeared and were successfully treated with local steroid injections. Later, a dermatologist advised treatment with cyclosporin A ( $3 \mathrm{mg} / \mathrm{kg} /$ day) and oral steroids, but they were

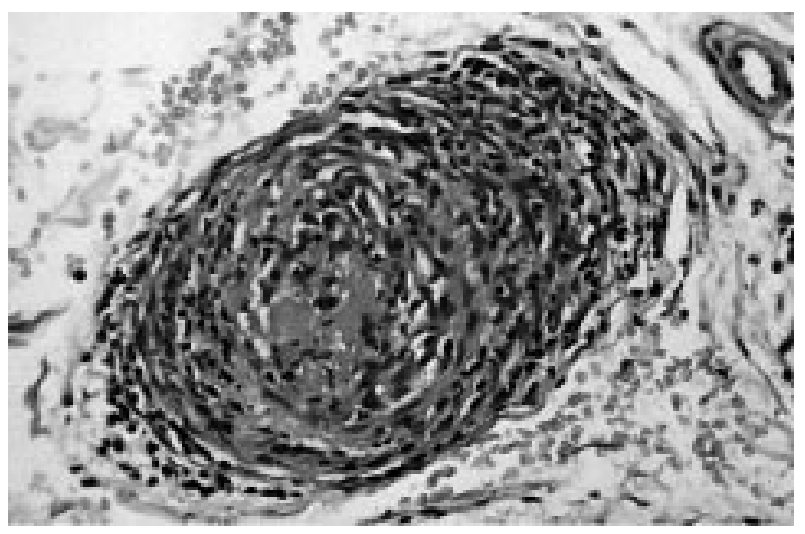

Figure 1 Skin biopsy with small vessel angiitis of the superficial derma characterised by cellular inflammatory infiltrate around and inside the vascular wall. Haematoxylin/eosin staining, $\times 400$ magnification. 


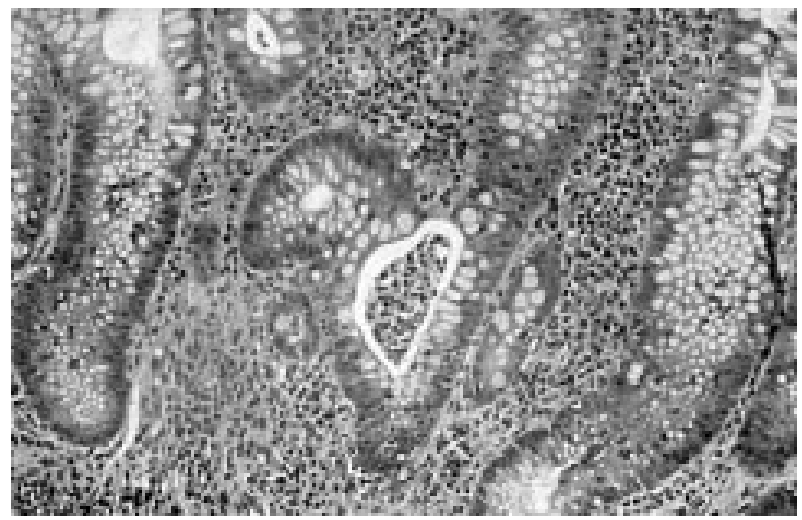

Figure 2 Colonic biopsy specimen showing severe mucosal inflammation, formation of crypt abscess, mild glandular atrophy, and distortion, suggesting an active phase of ulcerative colitis. Haematoxylin/eosin staining, $\times 400$ magnification.

without benefit. One year and half later the patient complained of abdominal pain and diarrhoea with rectal bleeding. An endoscopic evaluation showed inflammation of the rectal mucosa with bleeding deep ulcers, and a biopsy was suggestive of ulcerative colitis (fig 2). Treatment with oral sulfasalazine ( $3 \mathrm{~g} /$ day $)$ and rectal steroids was recommended, resulting in remission of the intestinal symptoms and disappearance of the skin lesions. At the one year follow up the patient is still well with $2 \mathrm{~g}$ /day of sulfasalazine; physical examination shows only scars and hyperpigmentation of the skin.

\section{DISCUSSION}

Leucocytoclastic vasculitis is a common disease whose histopathological features are inflammation of the postcapillary venules with neutrophilic infiltration and nuclear debris. ${ }^{1}$ It is believed to be an immune complex disease triggered by a large array of drugs, chemicals, infections, malignancies, and systemic and autoimmune diseases. ${ }^{2}$ Leucocytoclastic vasculitis usually affects only the skin, but sometimes systemic manifestations, such as fever, arthralgia, myalgia, and asthenia, can occur.

IBD (ulcerative colitis and Crohn's disease) can be associated with skin manifestations-nodules, pyoderma gangrenosus, livedo reticularis, and ulcers being the most common lesions. ${ }^{3}$ Association between leucocytoclastic vasculitis and ulcerative colitis is uncommon ${ }^{4-6}$ and, before our case, only two patients with cutaneous leucocytoclastic vasculitis preceding intestinal symptoms had been reported..$^{5}$ In these patients, skin lesions appeared one and five months before ulcerative colitis, respectively, whereas in our case the time lag was almost two years; maybe the use of steroids for the skin rash delayed the onset of the intestinal disease, although the treatment was not continuous.

We cannot exclude the possibility that the association between ulcerative colitis and leucocytoclastic vasculitis was coincidental in our patient, but we think that is unlikely as sulfasalazine dramatically ameliorated the abdominal symptoms and skin eruption. It is generally believed that leucocytoclastic vasculitis is due to the deposition of circulating immune complexes in the vessel wall. ${ }^{7}$ One possible explanation of the link between the two diseases is that the inflamed intestinal mucosa is the site of formation of immune complexes for the exposure of submucosal lymphoid tissue to faecal antigens. The other extraintestinal manifestations (ocular, musculoskeletal, etc) occurring in IBD can be explained similarly. However, our case provides a possible clue to answering the question: are ulcerative colitis and Crohn's disease primarily intestinal disorders or should they be considered to be inflammatory systemic illnesses? In our patient, the onset symptom was skin leucocytoclastic vasculitis followed, after a few months, by arthritis, and intestinal disease occurred only after a further two years. It is unlikely that skin and articular manifestations were sustained by an immune inflammatory process taking place in the intestinal mucosa. Thus it is likely that IBD is a systemic inflammatory disease and that, for unknown reasons, involvement of various tissues (skin, joints, bowel) may occur at different periods. Perhaps, extraintestinal manifestations in IBD are more common than reported as small lesions may be underdiagnosed by the clinicians.

Our case should prompt consideration of an underlying IBD when persistent skin leucocytoclastic vasculitis occurs without clinically apparent causes.

\section{Authors' affiliations}

F lannone, C Scioscia, A Musio, G Lapadula, DIMIMP-Sezione di Reumatologia, Università degli Studi di Bari, Italy

D Piscitelli, DAPEG-Sezione di Anatomia Patologica, Università degli

Studi di Bari, Italy

Correspondence to: Professor G Lapadula, DIMIMP-Sezione di Reumatologia, Padiglione V Chini, Piazza G Cesare 11, 70124 Policlinico, Bari, Italy; g.lapadula@reumbari.uniba.it

Accepted 21 January 2003

\section{REFERENCES}

1 Sams WM Jr, Thorne EG, Small P, Mass MF, McIntosh RM, Stanford RE. Leukocytoclastic vasculitis. Arch Dermatol 1976;1 12:219-26.

2 Sanchez NP, Van Hale HM, Su WP. Clinical and histopathologic spectrum of necrotizing vasculitis. Report of findings in 101 cases. Arch Dermatol 1985;121:220-4

3 Lebwohl $M$, Lebwohl $O$. Cutaneous manifestations of inflammatory bowel disease. Inflamm Bowel Dis 1998:4:142-8.

4 Peeters AJ, van den Wall Bake AW, Daha MR, Breeveld FC. Inflammatory bowel disease and ankylosing spondylitis associated with cutaneous vasculitis, glomerulonephritis, and circulating lgA immune complexes. Ann Rheum Dis 1990;49:638-40.

5 Newton JA, McGibbon DH, Marsden RA. Leucocytoclastic vasculitis and angio-oedema associated with inflammatory bowel disease. Clin Exp Dermatol 1984;9:618-23

6 Cribier B, Cuny JF, Schubert B, Colson A, Truchetet F, Grosshans E. Recurrent annular erythema with purpura: a new variant of leucocytoclastic vasculitis responsive to dapsone. $\mathrm{Br} J$ Dermatol 1996; 135:972-5.

7 Smoller BR, MCNutt NS, Contreras F. The natural history of vasculitis. What the histology tells us about pathogenesis. Arch Dermatol $1990 ; 126: 84-9$. 